\title{
Boussinesq Modelling of Waves and Currents in the Presence of Submerged Detached/Discontinuous Breakwaters
}

\author{
Mohammad Barzegar(1), Mohammad J. Ketabdari(2), Kourosh Kayhan(3), D. \\ Palaniappan ${ }^{(4)}$
}

(1) Texas A\&M University-Corpus Christi, Coastal and Marine System Science, 6300 Ocean Drive, Corpus Christi, TX 78412, USA

(2) Amirkabir University of Technology, Hafez Avenue, Tehran, IRAN

(3) DHI Technical and Marketing Manager, Tehran, IRAN

(4) Texas A\&M University-Corpus Christi, Department of Mathematics \& Statistics, 6300 Ocean Drive, Corpus Christi, TX 78412, USA

e-mail: devanayagam.palaniappan@tamucc.edu

\section{SUMMARY}

The effect of beach configurations with the main focus on the detached submerged breakwater on shoreline currents is investigated numerically. The Boussinesq equations are used to model the beach with a constant slope, continuous submerged breakwater, and discontinuous/detached submerged breakwater. Our numerical simulation results show that the transient rip currents are generated near the shoreline at the beach with constant slope while the continuous submerged breakwater structure creates a calm beach area along the shoreline. The presence of the gap in submerged breakwater changes the currents along the shoreline by generating rip currents with two pairs of vortices. One pair of vorticities, located around the gap, damage the breakwater by transmitting sediments along the breakwater foundation and eroding its surface. The second pair, created near the shoreline, erodes the shoreline due to sediment transportation and leads to a dangerous and unsafe situation for swimmers. The rip current creates five main critical areas with the maximum velocity towards the shoreline and offshore. The first set of three areas (numbered 1 , 2, 3) has an approximately average velocity of $1-1.25 \mathrm{~m} / \mathrm{s}$ towards the shoreline. One of these areas (numbered 2) is located close to the shoreline and the other two (numbered 1 and 3) are found to occur near the edge of the detached part of the breakwater. The second set of the two areas (numbered by 4 and 5) has the average velocity that is higher than $2.1 \mathrm{~m} / \mathrm{s}$ towards the offshore and is located at the beginning part of the rip neck. An approximately linear relationship between the returning velocity and the gap length is observed. As the gap length decreases the location of the areas (numbered 4 and 5) gets closer to the center of the gap. Our simulations indicate that the return velocity towards the offshore increases at the gap center while the gap length decreases. Furthermore, the velocity profiles have a sharp jump for gap length that is approximately smaller than $80 \mathrm{~m}$. Also, the return velocity at the gap center is related to the height of the breakwater. The breakwater that is higher (the breakwater height $d=4.2 \mathrm{~m}$ ) damps wave energy more than shorter 
breakwater and the return velocity decreases for this structure. For smaller heights ( $d=3.7$ and 3.2) damping is nearly the same and the returning flow varies depending on the available space through the gap. Specifically, the return velocity for $d=3.7$ is higher than that for $d=3.2$. The numerical results presented herein suggest that aggressive rip currents are generated in the case of detached submerged breakwater beach configurations.

KEY WORDS: $\quad$ detached submerged breakwater; rip current; Boussinesq equations; surf zone; numerical modelling.

\section{INTRODUCTION}

Several significant attempts have been made to model the effects of waves on surf zone, shoreline, sediment transport and shoreline protections [1-7]. Waves and currents change the shoreline characteristics by transporting sediments offshore and consequently, the transported sediments build sand bars along the shore. Due to the movement of water towards the offshore, gaps are created many times along the sand bars (Figure 1). The water evacuation towards the offshore from channels creates a very strong current called a rip current. Most of the beach structures, including discontinuous submerged breakwaters, can have similar effects on the shoreline currents. Due to the low visual impact on the environment, the submerged structures have been used as a defensive system to protect the shoreline from erosion. A detachment (discontinuous shape) along the submerged structures can induce stronger rip currents as well. It is known that the rip current changes the shoreline bathymetry by transferring the sediment offshore which additionally causes death to beachgoers. These are some of the motivating factors that demand studies about various consequences of rip currents created around discontinuous structures or san barriers.

Rip current is a narrow current that moves in the offshore direction. The evacuation of rip current begins from the interior of the surf zone and continues towards the exterior of the breaker zone line. Generally speaking, water carried towards the beach by waves is returned to the offshore by rip currents. Parallel and perpendicular currents are generated into the beach after breaking waves. The parallel current into the shoreline is known as the feeder current or longshore current. When two longshore currents are encountered from the opposite directions they return to offshore due to pressure gradient in the form of a narrow and strong current called a rip neck. The returning current starts to lose its energy by approaching the deep water (rip head). In general, terms, rip current consists of three parts: Feeder current, Rip neck, and Rip head (Figure 1).

One of the first field measurements of rip current was carried out by Shepard and Inman [8]. The cited study has shown the importance of the wave refraction due to the variations in the bathymetry and the rip current velocity was determined to be about $0.5-1 \mathrm{~m} / \mathrm{s}$. The rip currents have a key role in sediment transportation because of their high velocity. Short [9] and Cooke [10] investigated the effects of rip currents on shoreline shape and their importance for the sediment transport towards the offshore. For a three-year period, field observations were done over Southern Monterey Bay and California and the relation between alongshore rip channel migration and sediment transport was found [11].

Criado et al. [12] investigated rip current behavior under the waves, tidal level, and morphodynamic conditions. They noticed that a large wave creates the most intense rip currents. It is a known fact that conducting field research and direct measurements are 
associated with various difficulties. In view of this, several theoretical frameworks, including laboratory and numerical modelling, have been proposed to understand the rip current impacts [13-19]. For instance, Ketabdari et al. [17,18] simulated flow patterns induced by rip currents using discontinuous submerged breakwater model and observed pairs of vorticities. Extended Boussinesq equations were used for the wave generation in their study.

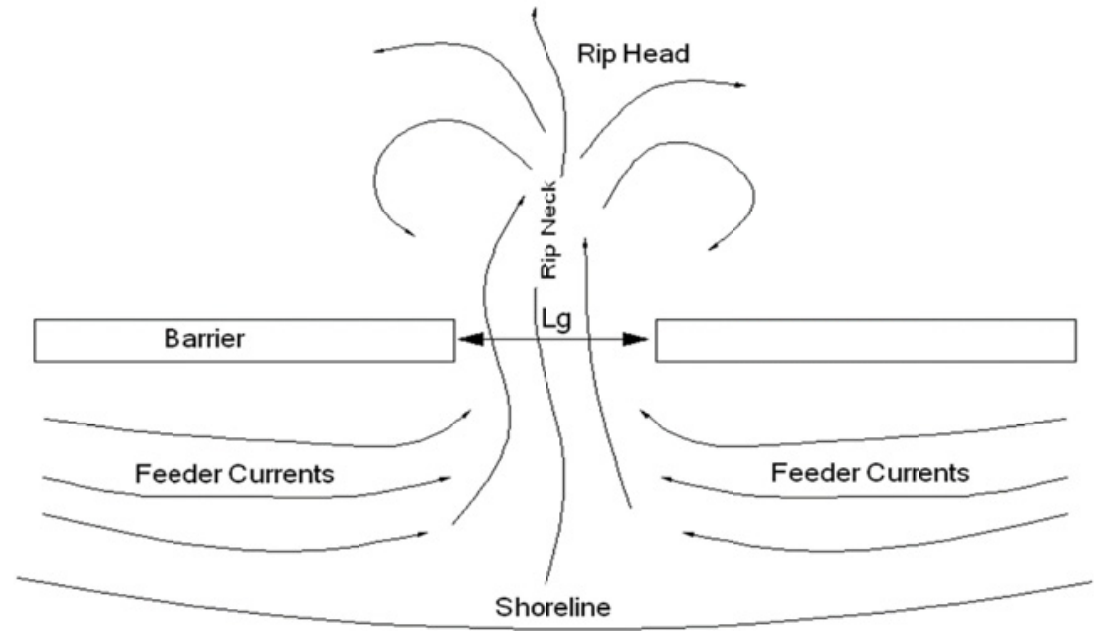

Fig. 1 A schematic of a rip current and a barrier

Haller et al. [20,21] performed experimental studies on the wave dispersion over sand bars in the context of nearshore dynamics. The results of these researches have shown that an increase in wave height over the sand bar happens in the middle of the channels in comparison to the still water situation. This, in turn, causes the waves to move and converge towards the longshore and, as a result, the rip current exits from the rip channel (discontinuous distance along the structures or sand barriers) towards the offshore. Dronen et al. [22] conducted a series of laboratory tests and observed interesting simulation results. In their tests, a system of the physical model consisting of bar/rip-channels attacked by regular and irregular waves was simulated under channel flow conditions. The results of their tests clearly depicted that, due to the longshore non-uniformity of the bar, a circulation cell on the barrier is created. In order to estimate water level variations and rip current velocities, a simplified model was presented by Belloti [23]. Wang et al. [24] simulated the rip currents created by the arc-shaped coastline. They found that the intensity of the rip current is related to the size of the arc-shaped coastline, height, and period of the wave.

The studies so far have focused on understanding the effects of the barrier gap length only on rip currents, even though immense researches have been done in the area of rip currents. In this paper, the effects of both gap length and height of the submerged breakwater on rip currents and wave parameters haves been modelled by Boussinesq equations for different bathymetry, the beach with a constant slope, beach with an alongshore continuous and discontinuous/detached submerged breakwater. By solving the enhanced Boussinesq equations via a numerical scheme, the study focusses on rip current characteristics due to these beach structures. The paper is organized as follows: in section 2., the theoretical framework for the model is recorded along with governing equations; a numerical scheme and implementation plan for solving the equations are provided in section 3.; descriptions of three beach structures considered in our models are also briefly illustrated in the same section; numerical simulation results and related graphical demonstrations appear in section 4. and, 
finally, in section 5., the main findings and observations of the present study are summarized along with conclusions.

\section{GOVERNING EQUATIONS}

The present numerical study is based on the two-dimensional enhanced Boussinesq equations for the surface elevation and the velocity components. In this set up the time-dependent governing equations in the $x y$ - plane for the free surface elevation $\eta$, and the depth-integrated velocity components $P$, and $Q$ in the Cartesian coordinate frame are as follows [25].

The continuity equation is written in the form:

$$
\frac{\partial \eta}{\partial t}+\frac{\partial P}{\partial x}+\frac{\partial Q}{\partial y}=0
$$

and the momentum equation in the $\mathrm{x}$ and $\mathrm{y}$-directions are:

$$
\begin{aligned}
& \frac{\partial P}{\partial t}+\frac{\partial}{\partial x}\left(\frac{P^{2}}{d}\right)+\frac{\partial}{\partial y}\left(\frac{P Q}{d}\right)+g d \frac{\partial \eta}{\partial x}+\frac{\partial R_{x x}}{\partial x}+\frac{\partial R_{x y}}{\partial y}+\frac{\tau_{x}}{\rho}-\frac{\partial}{\partial x}\left(d T_{x x}\right)-\frac{\partial}{\partial y}\left(d T_{x y}\right)+\Psi_{x}=0 \\
& \frac{\partial Q}{\partial t}+\frac{\partial}{\partial x}\left(\frac{P Q}{d}\right)+\frac{\partial}{\partial y}\left(\frac{Q^{2}}{d}\right)+g d \frac{\partial \eta}{\partial y}+\frac{\partial R_{x y}}{\partial x}+\frac{\partial R_{y y}}{\partial y}+\frac{\tau_{y}}{\rho}-\frac{\partial}{\partial x}\left(d T_{x y}\right)-\frac{\partial}{\partial y}\left(d T_{y y}\right)+\Psi_{y}=0
\end{aligned}
$$

Here $d=h+\eta$ is the total water depth and $\mathrm{h}$ is still water depth, $g$ is the gravitational acceleration and $\rho$ is the density. The terms denoted by $R_{x x}, R_{x y}$ and $R_{x x}$ account for additional convective momentum terms originating from the inclusion of the wave breaking [25]. The explicit forms of these quantities are given by:

$$
\begin{gathered}
R_{x x}=\frac{\delta}{1-\frac{\delta}{d}}\left(c_{x}-\frac{P}{d}\right)^{2} \\
R_{x y}=\frac{\delta}{1-\frac{\delta}{d}}\left(c_{x}-\frac{P}{d}\right) *\left(c_{y}-\frac{Q}{d}\right) \\
R_{y y}=\frac{\delta}{1-\frac{\delta}{d}}\left(c_{y}-\frac{Q}{d}\right)^{2}
\end{gathered}
$$

where $\delta=\delta(x, y, t)$ denotes the thickness of surface roller and $c_{x}$ and $c_{y}$ are the roller celerity components expressed in the form [25]:

$$
\begin{gathered}
c_{x}=\frac{\partial_{\eta}}{\partial_{x}} \frac{f_{v} \sqrt{g h}}{\sqrt{\left(\frac{\partial \eta}{\partial x}\right)^{2}+\left(\frac{\partial \eta}{\partial y}\right)^{2}}} \\
c_{y}=\frac{\partial_{\eta}}{\partial_{y}} \frac{f_{v} \sqrt{g h}}{\sqrt{\left(\frac{\partial \eta}{\partial x}\right)^{2}+\left(\frac{\partial \eta}{\partial y}\right)^{2}}}
\end{gathered}
$$

The factor $f_{v}$ appearing in (7) and (8) is the roller celerity factor determined by linear shallowwater theory. Inside the surf zone, the value $\mathrm{f}_{v}=1.3$ provides an appropriate approximation while $f_{v}=1$ is an appropriate value outside of the surf zone $[25,26]$. The additional terms in the momentum equations (2) and (3) are as described in Sorensen et al., [25]. The terms $\tau_{x}$ and $\tau_{y}$ are the bottom shear stress components written in the form:

$$
\begin{aligned}
& \tau_{x}=\frac{1}{2} f_{m} p \frac{\sqrt{P^{2}+Q^{2}}}{d^{2}} \\
& \tau_{y}=\frac{1}{2} f_{m} Q \frac{\sqrt{P^{2}+Q^{2}}}{d^{2}}
\end{aligned}
$$

with $f_{m}$ the friction factor. The stress terms $T_{x x}, T_{y y}, T_{x y}$ and $T_{y x}$ (in the eddy viscosity formulation) are given by: 


$$
\begin{gathered}
T_{x x}=2 v \frac{\partial}{\partial x}\left(\frac{P}{d}\right) \\
T_{y y}=2 v \frac{\partial}{\partial y}\left(\frac{Q}{d}\right) \\
T_{x y}=T_{y x}=v\left(\frac{\partial}{\partial y}\left(\frac{P}{d}\right)+\frac{\partial}{\partial x}\left(\frac{Q}{d}\right)\right)
\end{gathered}
$$

where $v$ is eddy viscosity, while the dispersive Boussinesq terms $\Psi_{x}$ and $\Psi_{y}$ are taken to be:

$$
\begin{aligned}
& \Psi_{x}=-\left(B+\frac{1}{3}\right) h^{2}\left(\frac{\partial^{3} P}{\partial x^{2} \partial t}+\frac{\partial^{3} Q}{\partial x \partial y \partial t}\right)-\frac{1}{6} h \frac{\partial h}{\partial x}\left(2 \frac{\partial^{2} P}{\partial x \partial t}+\frac{\partial^{2} Q}{\partial y \partial t}\right)-\frac{1}{6} h \frac{\partial h}{\partial y}\left(\frac{\partial^{2} Q}{\partial x \partial t}\right)-B g h^{2} \frac{\partial w}{\partial x} \\
& \Psi_{y}=-\left(B+\frac{1}{3}\right) h^{2}\left(\frac{\partial^{3} P}{\partial x \partial y \partial t}+\frac{\partial^{3} Q}{\partial y^{2} \partial t}\right)-\frac{1}{6} h \frac{\partial h}{\partial x}\left(\frac{\partial^{2} P}{\partial y \partial t}\right)-\frac{1}{6} h \frac{\partial h}{\partial y}\left(\frac{\partial^{2} P}{\partial x \partial t}+2 \frac{\partial^{2} Q}{\partial y \partial t}\right)-B g h^{2} \frac{\partial w}{\partial y}
\end{aligned}
$$

In the above, $B=1 / 15$ is the Boussinesq dispersion factor and $w$ is an auxiliary variable defined by:

$$
w=\frac{\partial}{\partial x}\left(h \frac{\partial \eta}{\partial x}\right)+\frac{\partial}{\partial y}\left(g h \frac{\partial \eta}{\partial y}\right)
$$

The governing equations are solved numerically by using MIKE 21BW, a software-based on the finite difference method to solve Boussinesq equations [18,27]. This numerical modelling tool has been successfully used for studies and analysis of wave disturbance in ports and coastal areas. In the following section, we provide the details of our numerical model and the implementation scheme for the understanding of currents in the vicinity of submerged detached breakwaters.

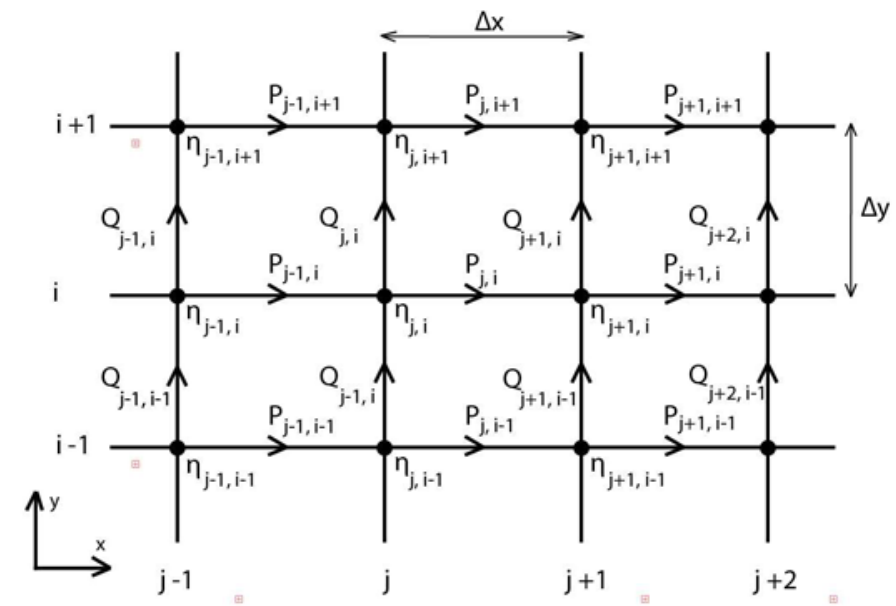

Fig. 2 Staggered grid notation in $x-y$ space

\section{NUMERICAL SCHEME AND MODEL IMPLEMENTATION}

The finite difference method is used to solve the governing equations stated in the previous section. The time integration to the equations is applied by using a time-central implicit scheme. A space-staggered rectangular grid is performed for spatial discretization as illustrated in Figure 2 where the water surface elevation and $(P, Q)$ components are defined in grid nodes between the adjacent grid nodes in the $\mathrm{x}$ and $\mathrm{y}$-directions, respectively. The meshes are numbered as $j=1,2, \ldots, m$ in the $\mathrm{x}$-direction and $i=1,2, \ldots, n$ in the $\mathrm{y}$-direction and the mesh size is taken to be $\Delta x$ in $x$-direction and $\Delta y$ in the $y$-direction, respectively. In order to solve the numerical model, a straightforward mid-centering for the finite-difference approximation of 
the spatial derivatives is used, except for the nonlinear convective terms, as described in detail by Madsen and Sorensen [28] (see section 4 of the cited paper).

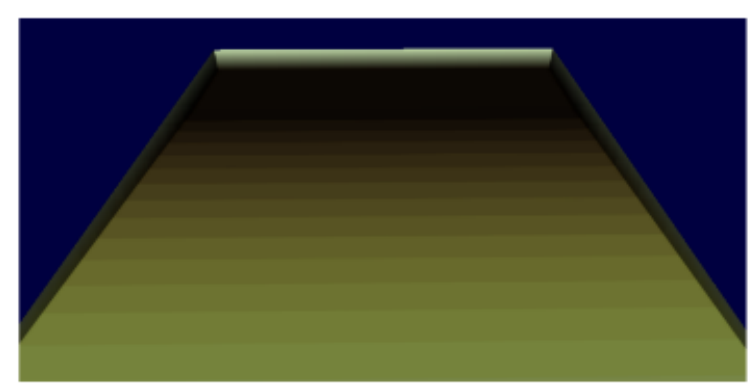

(a)

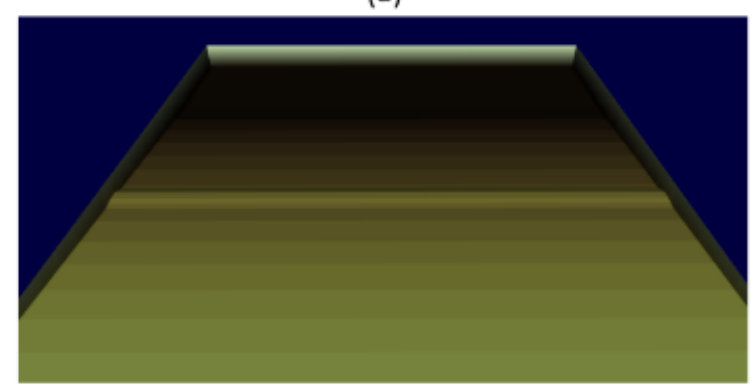

(b)

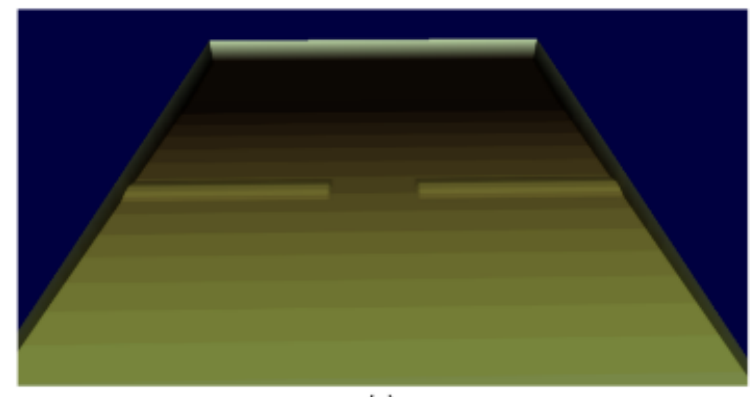

(c)

Fig. 3 The topography of the (a) beach with a constant slope, (b) beach with a continuous submerged breakwater and (c) a detached submerged breakwater with gap length of $\mathrm{Lg}=220 \mathrm{~m}$

In the present study, the effects of discontinuous submerged breakwaters into surf zone currents are investigated by considering three different beach configurations. The schematic topography of the three cases is portrayed in Figure 3 and is described as the beach with constant slope (Figure 3a), beach with longshore continuous (Figure 3b), and discontinuous submerged breakwaters (Figure 3c), respectively.

In all the considered models of the study, the area under research was $1200 * 1200 \mathrm{~m}^{2}$ and the beach slope of the three models was 3.3. In the numerical experiment, a regular wave with a wave height of $H=2.8 \mathrm{~m}$ and a wave period of $T=7.9 \mathrm{~s}$ is used. The wave generation line $[29,30]$ was located in front of the sponge layer [31] offshore as illustrated in Figure 4. The other sponge layer located at the land and the reflective boundary [32,33] was considered along the perpendicular sides of the shoreline. The grid sizes were taken to be $\Delta x=\Delta y=2 \mathrm{~m}$, the time steps was $\Delta t=0.12 \mathrm{~s}$ and the simulation period was $1200 \mathrm{~s}$. A constant friction factor of $f_{m}=0.03$ was used in the bed friction term. The Courant number, $C R$, was used for the numerical model according to the stability criteria $C R<1$ [34]. Specifically, the Courant 
number $C R \approx 0.85$ is used in the current simulation. The other numerical values utilized in the simulation for the three types of beach models are provided in the following subsections.

\subsection{BEACH WITH CONSTANT SLOPE}

In the first type of the model, the beach with constant slope is modelled to investigate the effects of the submerged breakwater on the surf zone currents. Here the $x$-axis is taken to be perpendicular to the shoreline and the points with coordinates $x=880 \mathrm{~m}$ and $280 \mathrm{~m}$ are denoted as shoreline and deep water, respectively.

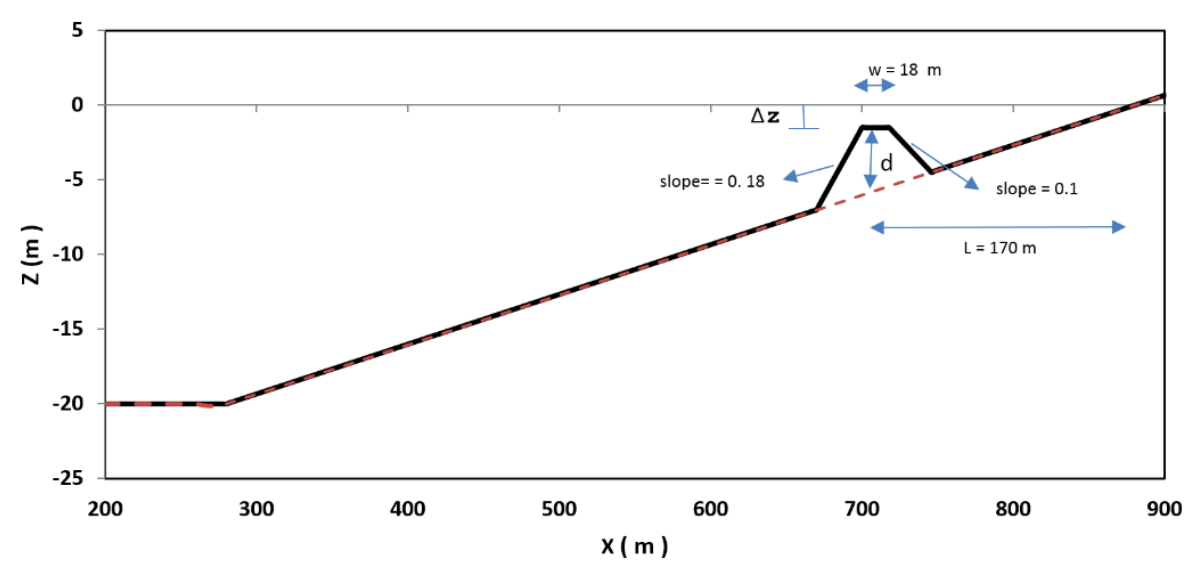

Fig. 4 A schematic of beach surface. The red dashed line shows the surface of the beach with a constant slope and the black line shows the beach with a submerged breakwater.

\subsection{BEACH WITH CONTINUOUS SUBMERGED BREAKWATER}

For this second beach configuration, the continuous submerged breakwater with a height of $d=4.2 \mathrm{~m}$ and a crest width of $w=18 \mathrm{~m}$ is considered. The center of breakwater crest is located at $L=170 \mathrm{~m}$ from the shoreline at the distance of $x=709 \mathrm{~m}$ (Figure 4). The distance of still water level to breakwater crest is $\Delta z=1.5 \mathrm{~m}$. The slope of the oncoming wave side of the breakwater is 0.18 and the shore side is 0.1 .

\subsection{BEACH WITH A DETACHED SUBMERGED BREAKWATER}

In the third category, the rip current created around the discontinuous/detached submerged breakwater with a gap at the center of the breakwater is modelled (Figure 5). The shape of the breakwater is the same as given in sub-section 4.2. The length of the gap, $L G$, is varied from 40 to $350 \mathrm{~m}$, presented in Table 1 for a total of eleven test cases. The effects of the breakwater height on the rip current are also investigated and the height of the breakwater between the crest surface and the water surface level is varied from $\Delta z=1.5,2$, and $2.5 \mathrm{~m}$ as given in Table 2 which equals $d=4.2,3.7$ and $3.2 \mathrm{~m}$, respectively. 


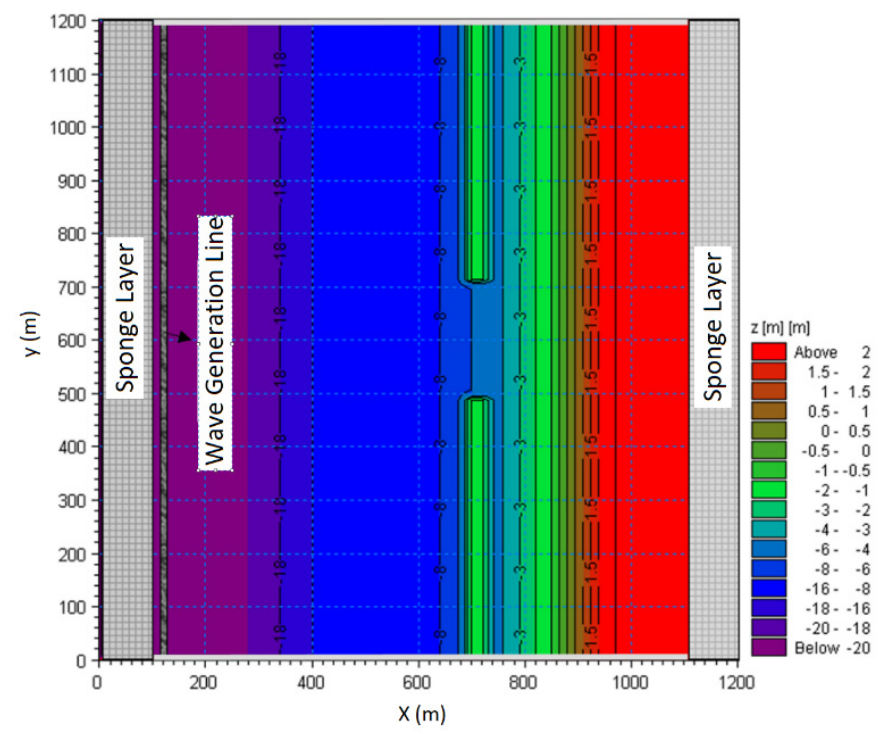

Fig. 5 Contour plot of bathymetry for the detached submerged breakwater with gap length of $L g=220 \mathrm{~m}$. The sponge layers are located on shoreline and offshore. The regular wave is generated in front of the sponge layer. The perpendicular sides to shoreline have a reflective boundary.

Table 1 Length of gap width in performed tests for the detached submerged breakwater

\begin{tabular}{|c|c|c|c|c|c|c|c|c|c|c|c|}
\hline Test No. & 1 & 2 & 3 & 4 & 5 & 6 & 7 & 8 & 9 & 10 & 11 \\
\hline Gap Length, LG (m) & $\mathbf{4 0}$ & $\mathbf{5 0}$ & $\mathbf{6 0}$ & $\mathbf{7 0}$ & $\mathbf{8 0}$ & $\mathbf{1 0 0}$ & $\mathbf{1 4 0}$ & $\mathbf{1 8 0}$ & $\mathbf{2 2 0}$ & $\mathbf{2 6 0}$ & $\mathbf{3 5 0}$ \\
\hline
\end{tabular}

Table 2 Performed tests on the detached submerged breakwater with gap width 60 meters; $(\Delta z)$ is denoted distance between water surface (in rest surface) and breakwater crest surface.

\begin{tabular}{|c|c|c|c|}
\hline Test No. & 1 & 2 & 3 \\
\hline $\boldsymbol{\Delta z}(\boldsymbol{m})$ & 1.5 & 2 & 2.5 \\
\hline
\end{tabular}

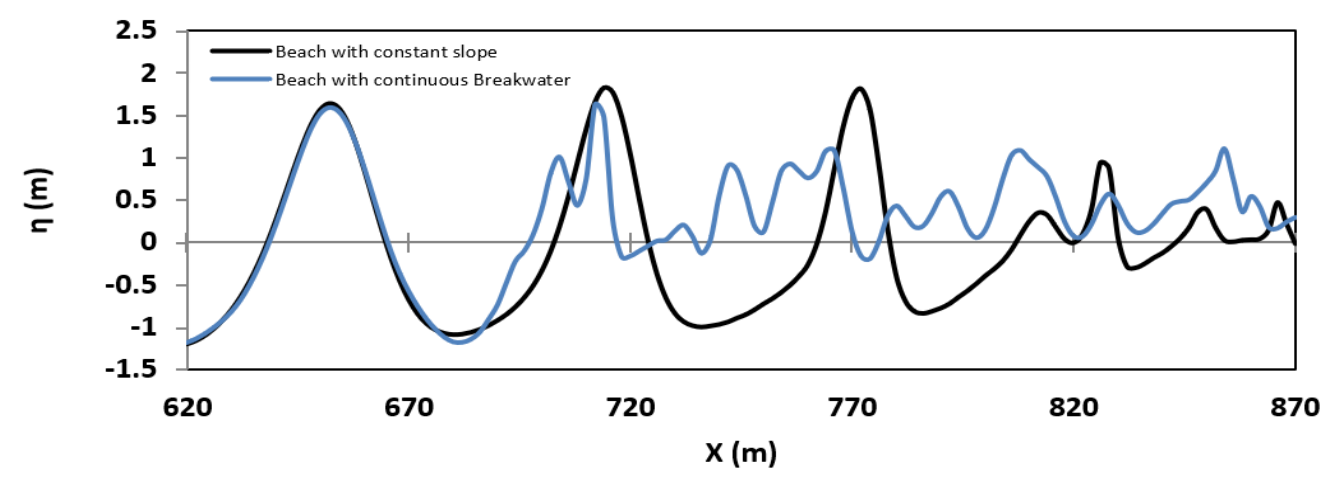

Fig. 6 The variability of wave height at the centerline of the model, $y=600 \mathrm{~m}$. The black line shows the wave height for the beach with constant slope or without submerged breakwater and blue line presents the data for the beach with an alongshore continuous submerged breakwater. 


\section{SIMULATION RESULTS}

We now proceed to the numerical simulation results for the three models discussed in the preceding section. First, the wave breaking occurs in the cases of the beaches with a constant slope and continuous submerged breakwater. Specifically, for a beach with a constant slope, the wave height increases by running up to them and breaks approximately at the distance of $x=780 \mathrm{~m}$ which is $100 \mathrm{~m}$ from the shoreline at a distance of $x=880 \mathrm{~m}$ as seen in Figure 6 . However, the submerged breakwater causes the wave breaking towards offshore at $x=710 \mathrm{~m}$ (that is $170 \mathrm{~m}$ from the shoreline) where the center of the submerged breakwater is located (Figure 6). Additionally, breaking the wave over the submerged breakwater decreases the wave energy and creates a calm and uniform current behind the breakwater as portrayed in Figure $7 \mathrm{a}$. On the other hand, the beach with constant slope creates unsteady eddies, roughly speaking transient rip currents, in close proximity to the shoreline as shown in Figures $7 \mathrm{~b}$ and $7 \mathrm{c}$.

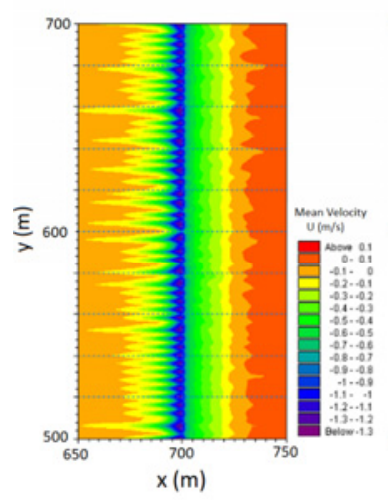

(a)

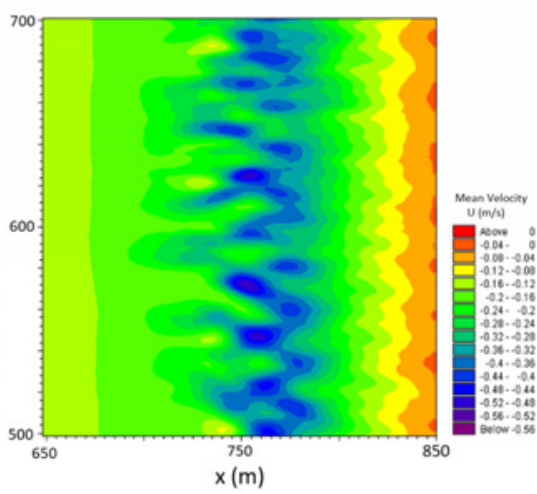

(b)

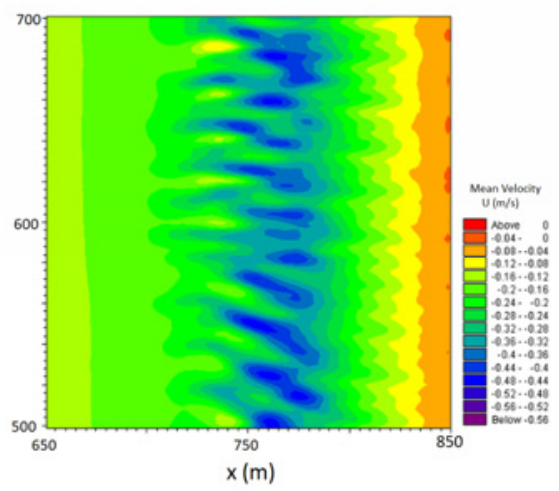

Fig. 7 Instantaneous snapshot of velocity for the (a) beach with a continuous submerged breakwater, (b) the constant slope at time $t=600 \mathrm{~s}$ and (c) constant slope at time $t=840 \mathrm{~s}$. The velocity toward offshore is considered as negative velocity.

Vast changes have been observed in our simulation for the case of detached/discontinuous submerged breakwater. The presence of the gap in the submerged breakwater allows the returning water to exit through the gap and then to move towards the offshore creating a rip current (see Figure 8). The occurrence of the rip current for the detached submerged breakwater with a gap length of $L g=220 \mathrm{~m}$ is displayed in Figure 9. The rip current creates five critical areas with high velocities indicated by numbers 1 to 5 in Figure 9a. In the areas designated by 1, 2, and 3 (displayed in amber color) the average flow velocity is between 1$1.25 \mathrm{~m} / \mathrm{s}$ moving towards the shoreline. However, in the other two areas, numbered by 4 and 5 , the average velocity is higher than $2.1 \mathrm{~m} / \mathrm{s}$ in the direction of the offshore. The location of areas 1 and 2, with coordinates $(480 \mathrm{~m}, 700 \mathrm{~m})$ and $(720 \mathrm{~m}, 700 \mathrm{~m})$, respectively, are found to be very close to the edge of the detachments on either side. These two significant areas can damage the breakwater by transporting the sediments along its foundation and eroding the lateral surfaces of the breakwater. As shown in Figure 9b, the oncoming wave symmetrically splits and bends towards the gap center between the breakwater creating longshore currents, also known as feeder currents. The feeder currents created on either side of the gap merge resulting in a strong jet flow towards the offshore, termed as a rip neck. This rapid rip neck flows further and decelerates as an expanding rip head towards the offshore, as displayed in Figure 9b. The circular pattern of the feeder current, the rip neck, and the rip head altogether generate two pairs of vorticities, as shown in Figure 10. The pair with positive vorticity (counter-clockwise orientation) covers the region between surf zone and the offshore, 
whereas the other pair with clockwise vorticity span the region between the surf zone and the shoreline. The existence of these vortex pairs in the vicinity of the shoreline along with the rip neck makes rip current increase the sediment transportation along the shoreline. Further, this phenomenon creates a dangerous environment for the swimmer due to high return velocities.

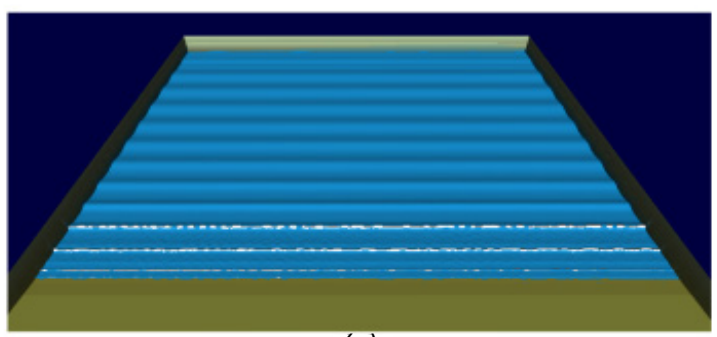

(a)

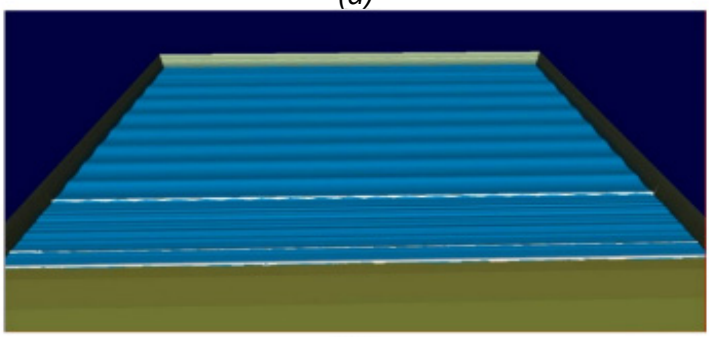

(b)

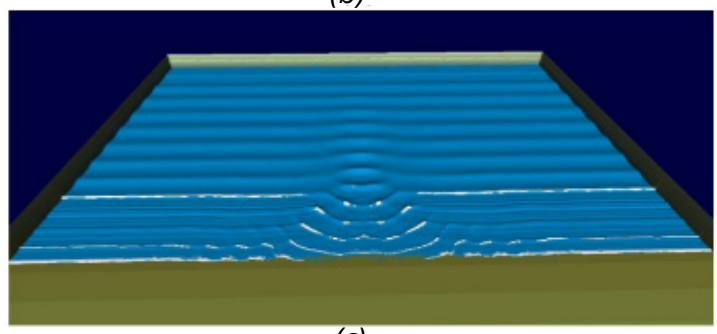

(c)

Fig. 8 Snapshots of the computed surface elevation for (a) the beach with a constant slope, (b) beach with continuous submerged breakwater and (c) detached submerged breakwater with gap length of $\mathrm{Lg}=220 \mathrm{~m}$. The surface roller is shown in the white color.

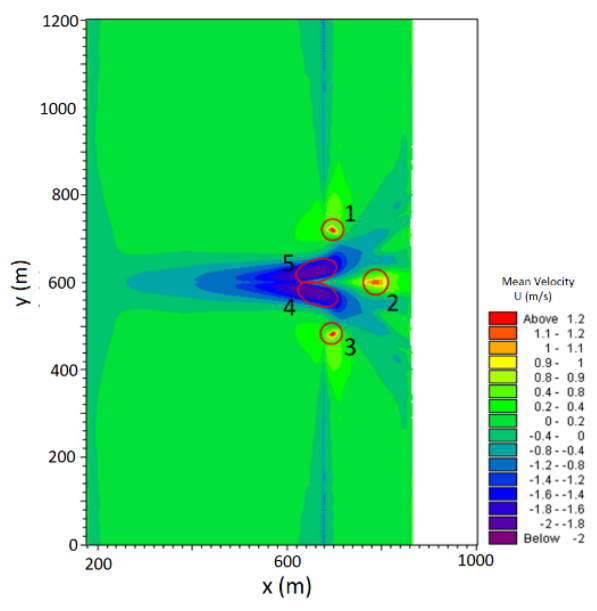

(a)

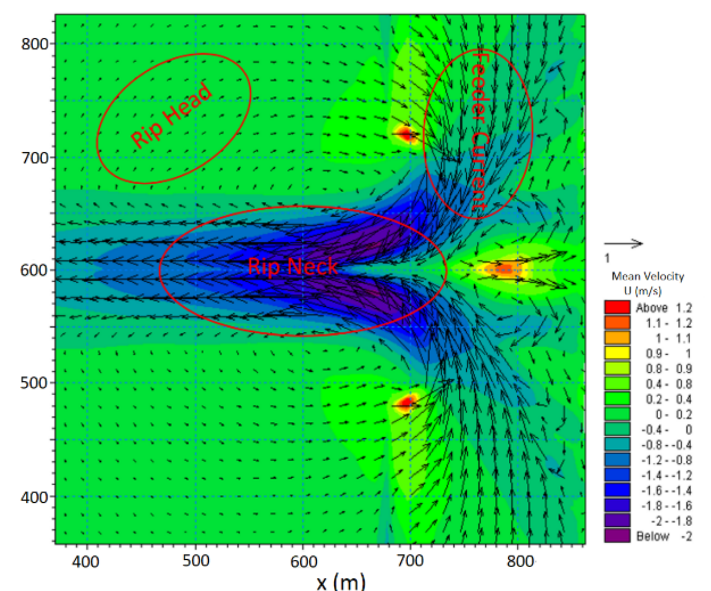

(b)

Fig. 9 Snapshot of velocity for (a) detached submerged breakwater with a gap length of $L g=220 \mathrm{~m}$. There are five areas with high velocities which present by amber color, velocity is toward the shoreline, and violet color, velocity is toward offshore; to better observation, (b) the subdomain of the total computed area is depicted. The velocity toward offshore is considered as negative velocity. 


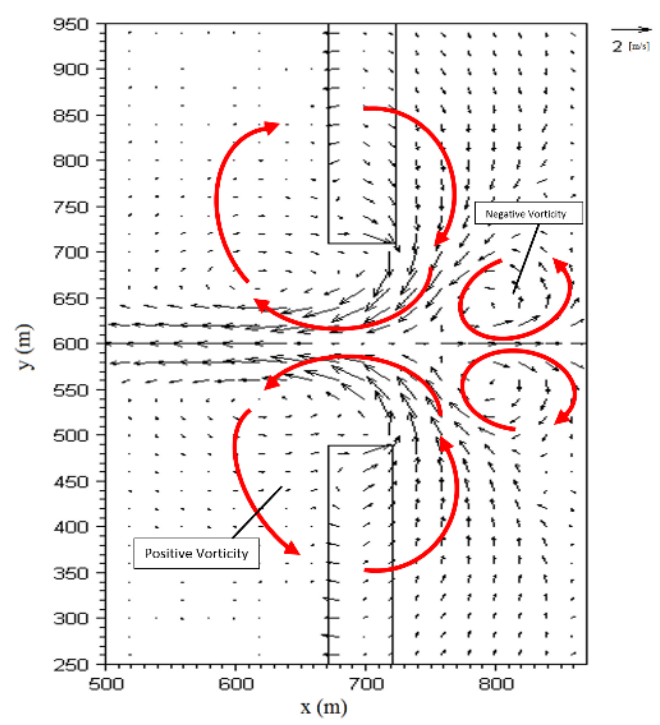

Fig. 10 Vector plot of the velocity field. The gap length was $L g=220 \mathrm{~m}$. The red arrows depict the created vorticities. The velocity toward offshore is considered as negative velocity.

It is observed that the maximum return velocity occurs near the converging point of the feeder currents (the regions indicated by 4 and 5 in Figure 9a) depending on the respective gap lengths. The plot of the maximum velocity Umax versus the gap length is displayed in Figure 11. Here Umax is the $\mathrm{x}$ component of the velocity with the positive direction pointing towards the shoreline. The graph shows that Umax varies linearly with the gap length approximately. One can see that the maximum velocity for gaps $40<L g<350$, ranges between $-1.76 \mathrm{~m} / \mathrm{s}<U<$ $2.67 \mathrm{~m} / \mathrm{s}$, where $U$ is. From the simulation data for the beach with the continuous submerged breakwater, the maximum return velocity was noted for $U=-1.3 \mathrm{~m} / \mathrm{s}$. These values indicate that the presence of the gap in discontinuous breakwater significantly increases the return velocity between 28 to 105 percent. The increase in return velocity is very vital for human safety and shoreline sediment transportation transferring offshore through the gap.

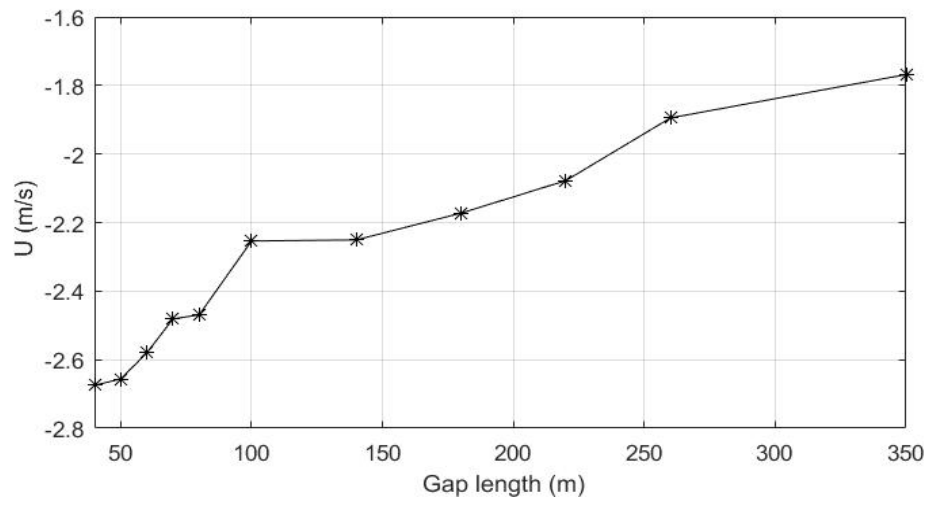

Fig. 11 Maximum return velocity (Umax) in critical areas of numbers 4 and 5 for different gap lengths. The velocity toward offshore is considered as negative velocity.

The numerical results for the return velocity at the gap center of the detached breakwater are presented in Figure 12 in all cases. It is seen that the magnitude of the return velocity increases for small gap lengths. The results further show that for small gap lengths, the return velocity increases, but the fluctuation domain decreases. In particular, for a gap length $<80 \mathrm{~m}$, the 
fluctuation in velocity is very small, which reveals that the rip current is more prominent in comparison with other situations.

As noticed earlier, the maximum return velocity has an approximately linear relation with the gap length, but the return velocity at the gap center is not linear and has a sharp jump for a gap length $\mathrm{Lg}$ smaller $80 \mathrm{~m}$ (See Figures 11 and 12). The difference of return velocity at the gap center and the maximum return velocity, $\Delta U$, is plotted in Figure 13. The graph shows that the velocity difference $(\Delta \mathrm{U})$ gets closer to zero for smaller gap length, which is $\Delta U \approx 0.07 \mathrm{~m} / \mathrm{s}$ for $L g=50$, see Figure 13. The smaller $\Delta U$ implies that the maximum return velocity (in the areas numbered 4 and 5) occurs very close to the gap center, as further illustrated by the velocity snapshot diagram in Figure 14. In other words, for a smaller gap length, the dangerous area of the rip neck is created in the vicinity of the gap center.

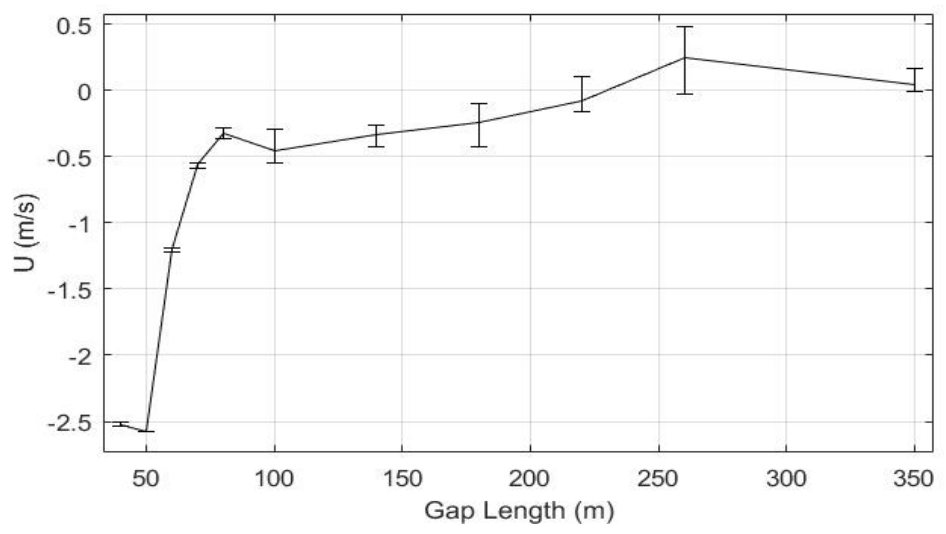

Fig. 12 The variability of return velocity at the gap center of the beach with a detached submerged breakwater. The vertical line shows the range of velocity fluctuation. Velocity toward offshore is considered as negative velocity.

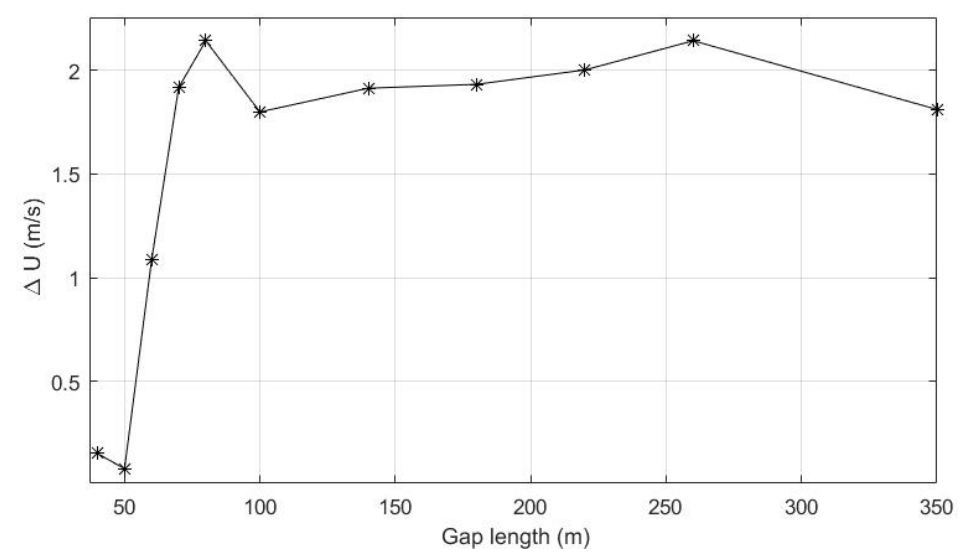

Fig. 13 The graph shows the change of $\Delta U$ for different gap lengths. $\Delta U=$ return velocity at gap center (Figure 12) - maximum return velocity in critical areas numbers 4 and 5 (Figure 11) 


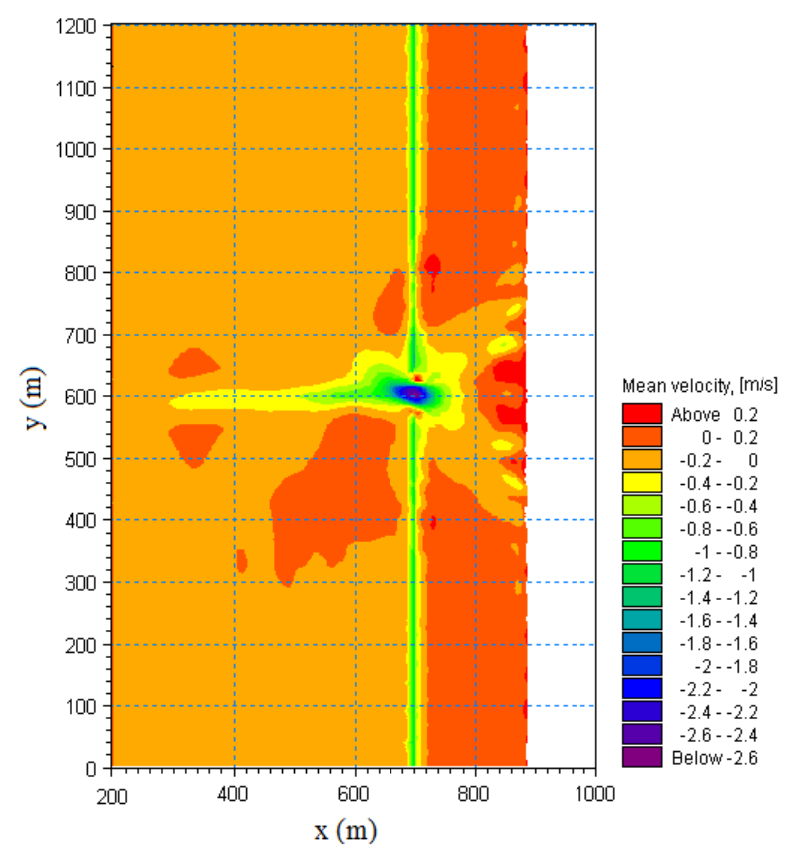

Fig. 14 Snapshot of velocity for detached submerged breakwater with a gap length of $L g=60 \mathrm{~m}$. The velocity toward offshore is considered as negative velocity.

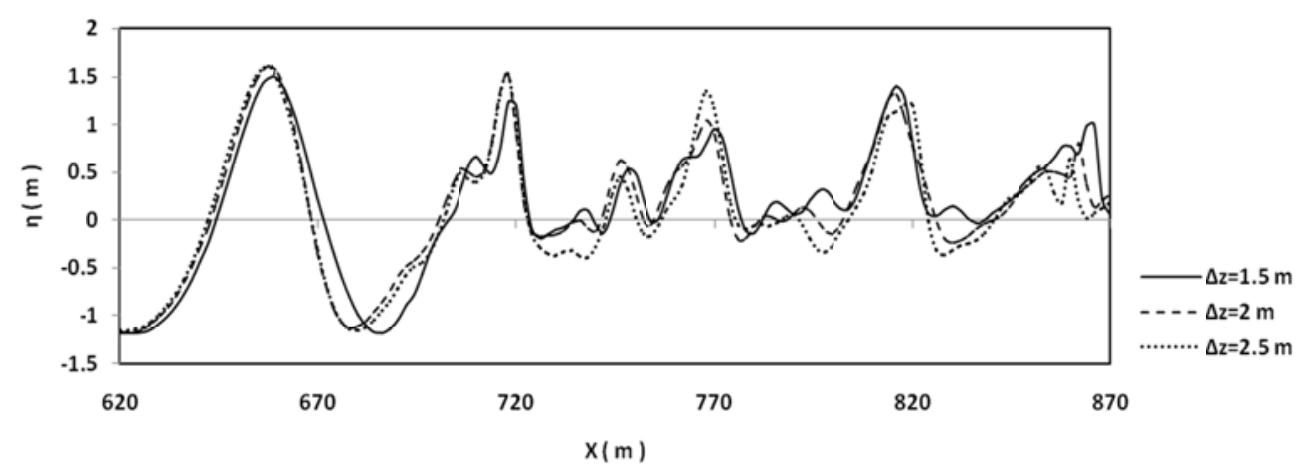

Fig. 15 The variability of wave height at the centerline of the model, $y=600 \mathrm{~m}$ for detached breakwater with gap length of $\mathrm{Lg}=60 \mathrm{~m}$ for different breakwater height shows the distance between the water surface and breakwater surface. The velocity toward offshore is considered as negative velocity.

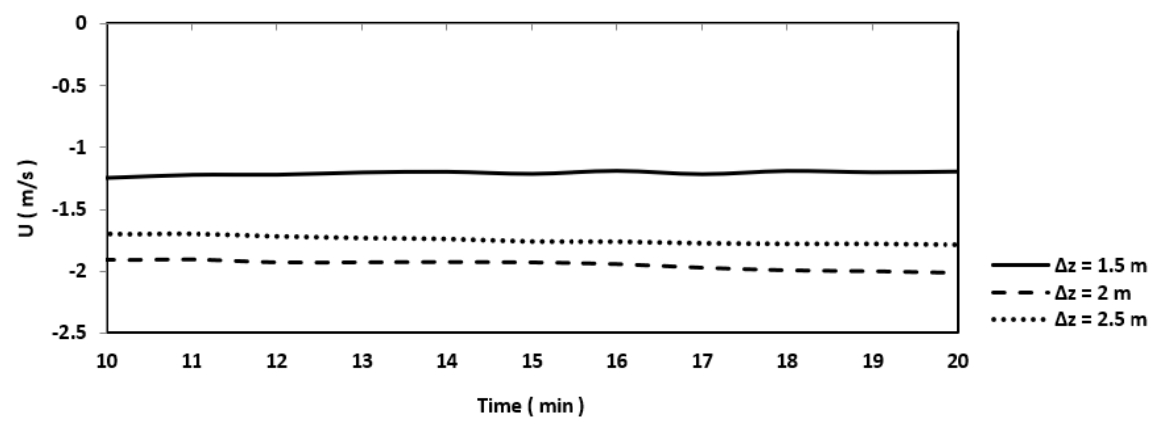

Fig. 16 The variability of return velocity at the gap center of the detached submerged breakwater with a gap length of $L g=60 \mathrm{~m}$ is shown for three breakwater heights. $\Delta z$ is the distance of still water level to breakwater crest. The velocity toward offshore is considered as negative velocity. 
The results that reflect the effect of the breakwater height on wave height and rip current return velocity at the center are now reported. The detached submerged breakwater with gap length is fixed at $L g=60$ for the research. The data presented in Figure 12 indicate that the average value of the return velocity is attained at the gap center when the gap length is $60 \mathrm{~m}-$ a justification for choosing this gap length. Breakwater with three different heights, see Table 2, is modelled and the results are portrayed in Figure 15 for the wave height $y=600 \mathrm{~m}$ in the domain $x=[620 \mathrm{~m} 870 \mathrm{~m}]$. Evidently, the breakwater damps wave energy by reflecting waves towards the offshore and by breaking them. Therefore, one can say that the higher the breakwater, the more damping of the wave energy. Thus, the wave energy in the vicinity of the breakwater has an impact on the returning current velocity because the main part of the rip neck is created at the edge of the breakwater crest towards the shoreline, see Figure 10. The wave height for $\Delta z=1.5 \mathrm{~m}(d=4.2 \mathrm{~m})$ is smaller at $x=718 \mathrm{~m}$ (see Figure 15) compared to the other values for $\Delta z$, thus making the return velocity smaller (since the wave energy is smaller), as can be seen in Figure 16. The cases of $\Delta z=2 \mathrm{~m}(d=3.7 \mathrm{~m})$ and $2.5 \mathrm{~m}(d=3.2 \mathrm{~m})$ have approximately the same wave height at the distance $x=718 \mathrm{~m}$. Having the same wave height (and the same energy level) suggests that the gap dimension has a significant impact on the return velocity. The return velocity for the case of $\Delta z=2 \mathrm{~m}$ is slightly greater than that for $\Delta z=2.5 \mathrm{~m}$ (Figure 16) because the former has a bigger breakwater height than the latter and affects more the return currents towards the offshore.

\section{CONCLUSION}

A numerical study providing an improved understanding of beach configurations impacting shoreline currents is carried out in this paper using the Boussinesq model. The beach structures considered in this research are a beach with (i) constant slope; (ii) continuous submerged breakwater; and (iii) detached/discontinuous breakwater. Our simulation results show that the transient rip currents are created near the shoreline of the beach with a constant slope, while the continuous submerged breakwater creates a calm area in the vicinity of the shoreline. In the case of a beach with detached breakwater, both the gap length parameter, $L g$, and the breakwater height have greater impacts on the rip currents. The presence of the gap changed the currents structure along the shoreline by generating permanent rip currents with a pair of longshore currents (current vortices), a strong jet towards the offshore, and a decelerating rip head. It is found that the longshore currents converge near the gap of the discontinuous breakwater while the rip neck currents diverge in the offshore inducing a lowvelocity rip head. The combination of convergence and divergence of returning currents creates a pair of vortices in the gap vicinity, which damages the breakwater foundation due to sediment transport and consequently eroding the breakwater surface. Another pair of vorticities created near the shoreline appears to create dangerous spots for swimmers and causes further shoreline eroding due to apparent sediment transportation.

A total of 5 critical rip current areas (see Section 4) occur with high magnitudes of velocity. Three of these areas, numbered 1, 2, and 3, have the average velocity between 1-1.25 $\mathrm{m} / \mathrm{s}$ towards the shoreline, and the other two areas, numbered 4 and 5 , have the average returning velocity that is higher than $2.1 \mathrm{~m} / \mathrm{s}$ towards the offshore. The results show that the returning velocity in the areas 4 and 5 increase (approximately) linearly for decreasing gap length. The comparison of the areas, numbered 4 and 5 , with gap center shows that the return velocity at the gap center does not have a linear relationship but has a sharp jump for $L g<80 \mathrm{~m}$. The numerical results for the difference of return velocity $\Delta U$ at the gap center and the maximum 
return velocity indicate that the areas numbered 4 and 5 are generally closer to the gap center for smaller gap length.

Breakwater height is yet another factor that affects the rip current characteristics. The return velocity decreases at the gap center for breakwater with small and large values of height. For $d=4.2 \mathrm{~m}$, the breakwater is higher and causes the wave energy damped over the breakwater more than other heights, $d=3.7 \mathrm{~m}$, and $3.2 \mathrm{~m}$, and the returning velocity at the gap center decreases in this case. For breakwater height of $d=3.2 \mathrm{~m}$ and $3.7 \mathrm{~m}$, the damping is less as compared to the higher breakwater and the returning flow varies depending on the available space through the gap. The return velocity at the gap center for $d=3.2 \mathrm{~m}$ is lower compared to when $d=3.7 \mathrm{~m}$ because the breakwater height in the former is smaller, so the intensity of the returning currents towards the offshore decreases.

\section{ACKNOWLEDGMENTS}

Special thanks to Danish Hydraulic Institute (DHI) for providing MIKE 21 model.

\section{REFERENCES}

[1] T. Aagaard, B. Greenwood, I. Nielsen, Mean currents and sediment transport in a rip channel, Marine Geology, Vol. 140, No. 1-2, pp. 25-45, 1997.

\section{https://doi.org/10.1016/S0025-3227(97)00025-X}

[2] P. Lin, P.L.F. Liu, A numerical study of breaking waves in the surf zone, Journal of fluid mechanics, Vol. 359, pp. 239-264, 1998. https://doi.org/10.1017/S002211209700846X

[3] M. Abbaspour, A.H. Javid, P. Moghimi, K. Kayhan, Modeling of thermal pollution in coastal area and its economical and environmental assessment, International Journal of Environmental Science \& Technology, Vol. 2, No. 1, pp. 13-26, 2015.

https://doi.org/10.1007/BF03325853

[4] M. Ghiasian, J. Carrick, D. Lirman, A. Baker, J. Ruiz-Merchan, J. Amendolara, B. Hasu, L. RhodeBarbarigos, Exploring coral reef restoration for wave-energy dissipation through experimental laboratory testing, Conf. in Coastal Structures, pp. 975-980, 2019.

[5] M. Ghiasian, M. Rossini, J. Amendolara, B. Hasu, S. Nolan, A. Nanni, N. Bel Had Ali, L. RhodeBarbarigos, Test-driven design of an efficient and sustainable seawall structure, Conf. in Coastal Structures, pp.1222-1227, 2019.

[6] D. Bogucki, B.K. Haus, M. Shao, The dissipation of energy beneath non-breaking waves, In Ocean Sciences Meeting 2020, AGU, 2020 February.

[7] D. Bogucki, B.K. Haus, M. Shao, The Response of the Boundary Layer to Weak Forcing, In Ocean Sciences Meeting 2020, AGU, 2020, February.

[8] F.P. Shepard, D.L. Inman, Nearshore water circulation related to bottom topography and refraction, Trans. Am. Geophys, Union 31, pp. 196-212, 1950.

https://doi.org/10.1029/TR031i002p00196

[9] A.D. Short, Handbook of Beach and Shoreface Morphodynamics, John Wiley and Sons, p. 379, 1999. 
[10] D.O. Cooke, The occurrence and geologic work of rip currents off southern California, Marine Geology, Vol. 9, pp. 173-186, 1970.

https://doi.org/10.1016/0025-3227(70)90013-7

[11] M.D. Orzech, E.B. Thornton, J.H. MacMahan, W.C. Oreilly, T.P. Stanton, Alongshore rip channel migration and sediment transport, Original Research Article, Marine Geology, Vol. 271, Issues 3-4, 15, pp. 278-291, 2010.

https://doi.org/10.1016/j.margeo.2010.02.022

[12] F.F. Criado-Sudau, D.D. Nemes, M.N. Gallo, Rip currents dynamic of a swell dominated microtidal beach, Journal of Coastal Research, 2019(SP92), pp. 121-127, 2019.

https://doi.org/10.2112/SI92-014.1

[13] M.X. Xie, Three-dimensional numerical modelling of the wave-induced rip currents under irregular bathymetry, Original Research Article, Journal of Hydrodynamics, Ser. B, Vol. 24, Issue 6, pp. 864-872, 2012. https://doi.org/10.1016/S1001-6058(11)60314-4

[14] J. Hatfield, A. Williamson, S. Sherker, R. Brander, A. Haven, Development and evaluation of an intervention to reduce rip current related beach drowning, Original Research Article, Accident Analysis and Prevention, Vol. 46, pp. 45-51, 2012.

https://doi.org/10.1016/j.aap.2011.10.003

[15] K. Fang, J. Yin, Z. Zou, Z. Liu, Boussinesq Modelling of Rip Currents on Barred Beach, Original Research Article, Procedia Engineering, Vol. 24, pp. 573-578, 2011.

https://doi.org/10.1016/i.proeng.2011.11.2698

[16] M.J. Austin, G. Masselink, T. Scott, P.E. Russell, Water-level controls on macro-tidal rip currents, Original Research Article, Continental Shelf Research, In Press, Accepted Manuscript, Vol. 12, pp. 201-213, 2013.

[17] M.J. Ketabdari, M.B.P. Lamouki, Numerical modelling of induced rip currents by discontinuous submerged breakwaters, International Journal of Marine and Science Engineering, Vol. 4, No. 1, pp. 15-24, 2014.

[18] M.J. Ketabdari, M.B.P. Lamouki, A. Moghaddasi, Effects of discontinuous submerged breakwater on water surface elevation, Ocean Systems Engineering, Vol. 5, No. 4, pp. 319329, 2015. https://doi.org/10.12989/ose.2015.5.4.319

[19] N. Kumar, G. Voulgaris, J.C. Warner, Implementation and modification of a threedimensional radiation stress formulation for surf zone and rip-current applications, Original Research Article, Coastal Engineering, Vol. 58, Issue 12, pp. 1097-1117, 2011.

https://doi.org/10.1016/j.coastaleng.2011.06.009

[20] M.C. Haller, R.A. Dalrymple, I.A. Svendsen, Experimental study of nearshore dynamics on a barred beach with rip channels, J. Geophys. Res., Vol. 107, No. 14, pp. 1-21, 2002.

https://doi.org/10.1029/2001JC000955

[21] M.C. Haller, R.A. Dalrymple, I.A. Svendsen, Experimental modelling of a rip current system, in Proceedings of the $3^{\text {rd }}$ International Symposium on Ocean Wave Measurement and Analysis, pp. 750- 764, Am. Soc. of Civ. Eng., Reston, Va., 1997b.

[22] N. Dronen, H. Karunarathna, J. Fredsoe, B.M. Sumer, R. Deigaard, An experimental study of rip channel flow, Coastal Engineering, Vol. 45, No. 3-4, pp. 223- 238, 2002. 


\section{https://doi.org/10.1016/S0378-3839(02)00035-2}

[23] G. Bellotti, A simplified model of rip currents systems around discontinuous submerged barriers, Coastal Engineering, Vol. 51, No. 4, pp. 323-335, 2004.

https://doi.org/10.1016/j.coastaleng.2004.04.001

[24] H. Wang, S. Zhu, X. Li, W. Zhang, Y. Nie, Numerical simulations of rip currents off arcshaped coastlines, Acta Oceanologica Sinica, Vol. 37, No. 3, pp. 21-30, 2018.

https://doi.org/10.1007/s13131-018-1197-1

[25] O.R. Sorenson, H.A. Schaffer, L.S. Sorenson, Boussinesq-type modeling using an unstructured finite element technique, Coastal Engineering, Vol. 50, pp. 181-198, 2004.

https://doi.org/10.1016/i.coastaleng.2003.10.005

[26] O.R. Sorenson, H.A. Schaffer and P.A. Madsen, Surf zone dynamics simulated by a Boussinesq type model. III, Wave-induced horizontal nearshore circulation, Coastal Engineering, Vol. 33, pp. 155-176, 1998.

https://doi.org/10.1016/S0378-3839(98)00007-6

[27] M. Barzegar, D. Palaniappan, Numerical study on the performance of semicircular and rectangular submerged breakwaters, Ocean Systems Engineering, Vol. 10, No. 2, pp. 201226, 2020. https://doi.org/10.12989/ose.2020.10.2.201

[28] P.A. Madsen, O.R. Sorenson, A new form of Boussinesq equations with improved linear dispersion characteristics, Part2. A slowly-varying bathymetry, Coastal Engineering, Vol. 18, pp. 183-204, 1992. https://doi.org/10.1016/0378-3839(92)90019-Q

[29] R.G. Dean, R.A. Dalrymple, Water Wave Mechanics for Engineers and Scientists, (Vol. 2), World Scientific Publishing Company, 1991. https://doi.org/10.1142/1232

[30] C.C. Mei, The Applied Dynamics of Ocean Surface Waves (Vol. 1), World scientific, 1989.

[31] J. Larsen, H. Dancy, Open boundaries in short wave simulations-a new approach, Coastal Engineering, Vol. 7, No. 3, pp. 285-297, 1983.

https://doi.org/10.1016/0378-3839(83)90022-4

[32] P.A. Madsen, Wave reflection from a vertical permeable wave absorber, Coastal Engineering, Vol. 7, No. 4, pp. 381-396, 1983.

https://doi.org/10.1016/0378-3839(83)90005-4

[33] E.F. Thompson, H.S. Chen, L.L. Hadley, Validation of numerical model for wind waves and swell in harbors, Journal of Waterway, Port, Coastal, and Ocean Engineering, Vol. 122, No. 5, pp. 245-257, 1996. https://doi.org/10.1061/(ASCE)0733-950X(1996)122:5(245)

[34] P. Ghadimi, M.B.P. Lamouki, Finite difference simulation of regular wave propagation over natural beach and composite barriers by Nwogu's extended Boussinesq equations, Progress in Computational Fluid Dynamics, an International Journal, Vol. 17, No. 4, pp. 212-220, 2017. https://doi.org/10.1504/PCFD.2017.085178 